\title{
Risk of falls and Effect of a Health Education Program in Prevention of Falls among Elderly in Geriatric Homes in Cairo, Egypt
} Ghada M Ismail $^{(1)}$, Hoda I Fahim ${ }^{(1)}$,Iman MA Bakr ${ }^{(1)}$, Ghada O Wassif ${ }^{(1)}$, Sarah A Hamza ${ }^{(2)}$ 1Department of Community, Environmental and Occupational Medicine, Ain Shams University

2 Geriatric Medicine \& Gerontology department, Faculty of Medicine, Ain Shams University, Cairo, Egypt.

\begin{abstract}
Background: Geriatric Falls are considered as one of the serious public health problems, as they are common causes of morbidity mortality and poor quality of life. Health education intervention programs for fall prevention improves knowledge and number of falls among elderly.

Aim: To assess risk of falling and home safety against falls among a group of elderly residents in Geriatric homes in Cairo, Egypt. Also, to explore the extent of falls' knowledge and evaluate the effectiveness of an intervention education program delivered to the elderly participants.
\end{abstract}

Methods: A quasi-experimental interventional study was conducted upon 120 elderly participants in 7 geriatric homes in different districts in Cairo. The interview questionnaire included sociodemographic, general geriatric health, falls' risk assessment, geriatric home safety, falls' knowledge and falls' history sections. Educational Intervention was provided as a series of lectures to the elderly in the selected geriatric homes about falls related topics. Participants were interviewed for 3 times, before the intervention (pretest), after the intervention (posttest), and 6 months later (follow up posttest)

Results: There was statistical significant improvement in the knowledge scores of geriatric participants regards different falls' topics in the posttest and follow up (6 months posttest) after implementation of the education intervention in comparison with the pretest scores $(P=0.00)$. Elderly participants who experienced falling decreased from $(35.8 \%)$ in the pre-test to $(27.4 \%)$ in the 6 months post-test after the education intervention.

Conclusions: The health education intervention proved to be effective in increasing knowledge and reducing number of falls among geriatric participants.

\section{Background}

Population aging is a global challenge, the percent of older people in Egypt was $6.9 \%$ in 2015, projected to be $9.2 \%$ in 2021 , and it is expected to reach $20.8 \%$ in 2050. This means that, around 20 million Egyptians will be categorized as elderly by that time ${ }^{(1)}$. Prevalence of falls among elderly in Egypt is estimated to be $(33.3 \%)^{(2)}$. Geriatric Falls are considered as one of the most common and serious public health problems, as they are common causes of morbidity and mortality, loss of independence, and poor quality of life ${ }^{(3)}$.Its reported by the CDC that one in every three adults age 65 and older falls each year ${ }^{(4)}$.Institutionalized elderly people are three times more likely to fall than those who live in the community, this may be explained by loss of family relationships, lower functional capacity and physical inactivity due to social isolation ${ }^{(5)}$ 
Although they are predictable and preventable events ${ }^{(6)}$, preventing them can be challenging because of their multifactorial short and long-term causes ${ }^{(7)}$

Elderly are often not aware of their own fall-risk or may realize their risk of falling but they have short of knowledge on how to prevent falls ${ }^{(8)}$

Health education intervention programs for fall prevention improves knowledge, attitude, preventive behavior and number of falls among elderly ${ }^{(9)}$ and can reduce the risk of their recurrent falls ${ }^{(10)}$. Those health education messages should focus on increasing awareness of specific fall prevention practices and their importance in reducing Risk of falls, and promoting the well-being of the elderly ${ }^{(11)}$

\section{Aim}

To assess risk of falling and home safety against falls among a group of elderly residents in Geriatric homes in Cairo, Egypt. Also, to explore the extent of falls knowledge and evaluate the effectiveness of an intervention education program delivered to the elderly participants.

\section{Methods}

Study design

A quasi-experimental interventional involved elderly participants aged 60 or above years old from both sexes residing Geriatric homes in Cairo

\section{Sample size}

It was calculated using PASS sample size calculation program based on a study carried out by (El-Gilany etal., 2013) ${ }^{(12)}$ and estimated improvement in total score in post-intervention compared to pre-intervention equal 10.

A sample size of 115 produces a two sided $95 \%$ confidence interval with a distance from the mean paired difference to the limits that is equal to 10 when the estimated standard deviation of the paired differences is 50.0

\section{Sampling technique:}

Convenient sample of 120 elderly participants from 7 geriatric homes in different districts in Cairo

\section{Study tools:}

Four different tools were used to assess elderly participants: geriatric health questionnaire, falls` risk self-assessment tool, home fall prevention checklist for older adults and falls` risk awareness questionnaire (FRAQ)

The questionnaire was interview one. It included sociodemographic, general geriatric health, falls`risk assessment, geriatric home safety, falls` knowledge and falls` history sections.

The general geriatric health of participants was assessed by geriatric health questionnaire.

Elderly participants falls risk was assessed by CDC falls risk self-assessment tool ${ }^{(13)}$. The tool consisted of 12 statements, answer (No) scores zero, while answer (yes) scores one. Elderly participant Scoring 4 or more was considered at risk of falling.

Geriatric homes`safety against falls was evaluated by the CDC home fall prevention checklist for older adults (14). The checklist has 17 self-reported items reflecting home safety in geriatric homes, Presence of hazard scores "1", while absence of the hazard scores "0". The higher the home safety score, the more risky is the environment, scoring 5 or more is considered risky geriatric home environment.

The geriatric participants` socio- demographic characteristics, general geriatric health, falls` risk assessment and geriatric home safety data were collected once in the pretest.

Elderly participants falls`risk awareness was assessed by falls`risk awareness questionnaire (FRAQ) ${ }^{(15)}$, other questions about falls' knowledge were added by the research team.

The knowledge questions included questions about falls' general information, falls risk factors (health risk Factors, medication and environmental risk factors of falls), complications and prevention.

Questions about awareness and knowledge about falls were asked 3 times: pretest (before the education intervention), posttest (after the education intervention) and 6 months posttest (follow up).

The Answer categories of all knowledge questions were true, false, don't know. The data were recoded into correct and wrong answers, correct answer scored 1, wrong and don't know answers scored 0. Score was given to each category of falls knowledge: general information, risk factors, complications and prevention Questions about falls were asked twice, once in the pretest and the second time 6 months posttest

\section{Educational Intervention}

It was provided as a series of power point presentation lectures to the elderly in the selected geriatric homes about falls related topics such as: Definition, Risk Factors, Consequences, and Susceptible Geriatrics to falls, Falls Prevention and Safe Geriatric Home Environment.

The educational sessions were carried by the researcher in each of the selected geriatric homes.

Health education materials as posters and pamphlets about important points of falls prevention were disseminated at the end of the education intervention, pamphlet were distributed to all elderly participants and posters were hang in each of the selected geriatric homes.

\section{Field Study duration:}

From May 2016 till the end of February 2017.

\section{Data management:}

Data was revised, coded and entered on computer. Both descriptive and inferential statistics were done using SPSS program version 20. Descriptive statistics used were frequency and percentage for all qualitative data. Mean and standard deviation for all quantitative data. Inferential statistics used include Student paired T test, McNemar test and multiple linear regression. 


\section{Results}

The study results showed that about half of the elderly participants were females $(50.8 \%)$. The mean age of the participants was $69.3 \pm 6.2$ where more than three quarters of them $(78.3 \%)$ were in the age group (6074), More than half of them $(51.6 \%)$ were divorced or widowed. More than one third (35.8\%) finished their university education (Table 1)

Table 1: Demography of the study population

\begin{tabular}{|c|c|}
\hline Variable & № (\%) \\
\hline \multicolumn{2}{|l|}{ Gender: } \\
\hline Male & $59(49.2)$ \\
\hline Female & $61(50.8)$ \\
\hline \multicolumn{2}{|l|}{ Age Groups: } \\
\hline Young old $(60-74)$ & $94(78.3)$ \\
\hline Old old $(\geq 75)$ & $26(21.7)$ \\
\hline $\begin{array}{l}\text { (Mean } \pm \text { S.D. }) \\
\text { (Range) }\end{array}$ & $\begin{array}{l}(69.3 \pm 6.2) \\
(60-84)\end{array}$ \\
\hline \multicolumn{2}{|l|}{ Marital Status: } \\
\hline Single & $25(20.8)$ \\
\hline Married & $33(27.5)$ \\
\hline Divorced/ Widow & $62(51.7)$ \\
\hline \multicolumn{2}{|l|}{ Education: } \\
\hline Illiterate & $23(19.2)$ \\
\hline Basic & $38(31.7)$ \\
\hline Secondary & $16(13.3)$ \\
\hline University/ Post-graduate & $43(35.8)$ \\
\hline
\end{tabular}

Concerning fall risk assessment (FRA)among elderly participants, more than two third $(69.2 \%)$ were at risk of falling, where the majority of the elderly participants $(80.0 \%)$ mentioned that they" pushed with their hands to stand up from a chair", and more than half of which $(59.2 \%)$ were "worried about falling" and "had trouble to step up into a curb", while (43.3\%) sometimes feel unsteady during walking and more than one third $(35.8 \%)$ experienced a previous fall in the last 6 months (Table 2).

The mean score of home safety among elderly participants is $(3.4 \pm 2.1)$, where $(27.5 \%)$ of elderly participants reported risky geriatric home environment, concerning the most important environmental risk factors of falls in geriatric homes, where $(60.8 \%)$ of elderly participants reported slippery bathroom floors, $(41.7 \%)$ reported that the light was hard to reach, $(40.0 \%)$ reported broken or uneven steps while (37.5\%) reported throw rugs on the floor (Table 3 )

Regarding the effect of the health education intervention program upon 'knowledge and falls of elderly participants, the current study revealed that there was a statistically significant improvement in the knowledge scores of elderly participants in both postintervention and follow-up phases as compared to preintervention phases $(\mathrm{P}<0.01)$. In addition, there was a reduction in the percentage of elderly participants who experienced falls in the post-intervention phase as compared to the pre-intervention phase, However, this
Table 2: Falls` risk assessment (FRA) among elderly participants $(n=120)$ :

\begin{tabular}{|c|c|c|}
\hline \multicolumn{2}{|l|}{ Variable } & № (\%) \\
\hline \multicolumn{2}{|c|}{ Previous Fall in the last 6 months. } & $43(35.8)$ \\
\hline \multicolumn{2}{|c|}{ Has been advised to use cane or walker. } & $42(35.0)$ \\
\hline \multicolumn{2}{|c|}{ Sometimes feel unsteady during walking. } & $52(43.3)$ \\
\hline \multicolumn{2}{|c|}{$\begin{array}{l}\text { Holding onto furniture during walking at } \\
\text { home. }\end{array}$} & $45(37.5)$ \\
\hline \multicolumn{2}{|c|}{ Worried about falling. } & $71(59.2)$ \\
\hline \multicolumn{2}{|c|}{$\begin{array}{l}\text { Push up with his hands to stand up from a } \\
\text { chair. }\end{array}$} & $96(80)$ \\
\hline \multicolumn{2}{|c|}{ Has some trouble stepping up into a curb. } & $71(59.2)$ \\
\hline \multicolumn{2}{|c|}{ Has to rush to the toilet often. } & $44(36.7)$ \\
\hline \multicolumn{2}{|c|}{ Has lost some feeling in feet. } & $17(14.2)$ \\
\hline \multicolumn{2}{|c|}{$\begin{array}{l}\text { Takes medicine that lead to dizziness or } \\
\text { fatigue. }\end{array}$} & $15(12.5)$ \\
\hline \multicolumn{2}{|c|}{ Often feels sad or depressed. } & $28(23.3)$ \\
\hline \multirow[t]{2}{*}{$\begin{array}{l}\text { Risk of fall score } \\
=12\end{array}$} & $\begin{array}{l}\text { Mean } \pm \text { SD } \\
(4.5 \pm 2.2)\end{array}$ & $\begin{array}{l}\text { Range } \\
(0-10)\end{array}$ \\
\hline & № & $\%$ \\
\hline At risk of falling $(\geq 4)$ & 83 & 69.2 \\
\hline $\begin{array}{l}\text { Not at risk of falling } \\
(<4)\end{array}$ & 37 & 30.8 \\
\hline
\end{tabular}

Table 3: Self-reported environmental risk factors of falls in geriatrics homes by elderly participants

\begin{tabular}{|c|c|c|}
\hline \multicolumn{2}{|l|}{ Variable } & № $(\%)$ \\
\hline \multicolumn{3}{|l|}{ FLOORS: } \\
\hline \multicolumn{2}{|c|}{ Walk around furniture during walking. } & $39(32.5)$ \\
\hline \multicolumn{2}{|c|}{ Throw rugs on the floor. } & $45(37.5)$ \\
\hline \multicolumn{2}{|l|}{ Objects on the floor. } & $30(25.0)$ \\
\hline \multicolumn{2}{|l|}{ Wires or cords on the floor. } & $14(11.7)$ \\
\hline \multicolumn{3}{|l|}{ STAIRS AND STEPS: } \\
\hline \multicolumn{2}{|l|}{ Objects on the stairs. } & $0(0.0)$ \\
\hline \multicolumn{2}{|l|}{ Broken or uneven steps. } & $48(40.0)$ \\
\hline \multicolumn{2}{|l|}{ Absent lightening. } & $9(7.5)$ \\
\hline \multicolumn{2}{|c|}{ One light switch for the stairs } & $6(5.0)$ \\
\hline \multicolumn{2}{|c|}{ Burned out bulb. } & $12(10.0)$ \\
\hline \multicolumn{2}{|l|}{ Loose or torn carpet. } & $0(0.0)$ \\
\hline \multicolumn{2}{|l|}{ Loose or broken handrails. } & $32(26.7)$ \\
\hline \multicolumn{3}{|l|}{ KITCHEN: } \\
\hline \multicolumn{2}{|c|}{ The things used often are on high shelves. } & $19(15.8)$ \\
\hline \multicolumn{2}{|c|}{ Needs a kitchen step stool to reach things. } & $11(9.2)$ \\
\hline \multicolumn{3}{|l|}{ BATHROOMS: } \\
\hline \multicolumn{2}{|l|}{ Shower floor is slippery. } & $73(60.8)$ \\
\hline \multicolumn{2}{|c|}{ Needs some support in the toilet. } & $7(5.8)$ \\
\hline \multicolumn{3}{|l|}{ BEDROOMS: } \\
\hline \multicolumn{2}{|l|}{ The light is hard to reach. } & $50(41.7)$ \\
\hline \multicolumn{2}{|c|}{ The path from the bed to the bathroom is dark. } & $15(12.5)$ \\
\hline \multirow[t]{2}{*}{$\begin{array}{l}\text { Home Safety Score } \\
=17\end{array}$} & $\begin{array}{c}\text { Mean } \pm \text { SD } \\
(3.4 \pm 2.1)\end{array}$ & $\begin{array}{l}\text { Range } \\
(0-9)\end{array}$ \\
\hline & № & $\%$ \\
\hline Risky environment $(\geq 5)$ & 33 & $(27.5)$ \\
\hline Safe environment $\quad(<5)$ & 87 & $(72.5)$ \\
\hline
\end{tabular}


difference was statistically insignificant $(\mathrm{P}>0.05)$.

On the other hand, the mean number of falls among elderly participants significantly decreased in the postintervention phase as compared to the pre-intervention phase $(\mathrm{P} \leq 0.05)($ table 4$)$
Multiple linear regression analysis displaying independent predictors of risk of falling among elderly participants, it was revealed that age, vision impairment, number of medication, previous falling and home safety are significant independent predictors of predicted risk of falling among elderly participants $(\mathrm{P}<0.05)($ table 5)

Table 4: Effect of the education intervention on knowledge and falls of elderly participants in the post-intervention and follow up phases as compared to the pre-intervention

\begin{tabular}{|c|c|c|c|c|c|c|c|c|}
\hline \multirow[b]{2}{*}{$\begin{array}{l}\text { Adequate } \\
\text { knowledge about: }\end{array}$} & \multicolumn{2}{|c|}{$\begin{array}{l}\text { Pre-test } \\
(\mathrm{n}=120)\end{array}$} & \multicolumn{2}{|c|}{$\begin{array}{l}\text { Post-test } \\
(\mathrm{n}=120)\end{array}$} & \multicolumn{2}{|c|}{$\begin{array}{l}\text { Follow up } \\
(\mathrm{n}=106)\end{array}$} & \multicolumn{2}{|r|}{ P\# } \\
\hline & № & $\%$ & № & $\%$ & № & $\%$ & Pre-Post & Pre-Follow up \\
\hline $\begin{array}{l}\text { Health related } \\
\text { Factors }\end{array}$ & 12 & 10 & 115 & 95.8 & 94 & 78.3 & $<0.01 *$ & $<0.01 *$ \\
\hline $\begin{array}{l}\text { Medication Related } \\
\text { factors }\end{array}$ & 13 & $\begin{array}{c}10 . \\
8\end{array}$ & 115 & 95.8 & 89 & 74.2 & $<0.01 *$ & $<0.01 *$ \\
\hline $\begin{array}{l}\text { Environmental } \\
\text { Factors }\end{array}$ & 31 & $\begin{array}{c}25 . \\
8\end{array}$ & 117 & 97.5 & 101 & 84.2 & $<0.01 *$ & $<0.01 *$ \\
\hline Complications & 26 & $\begin{array}{c}21 . \\
7\end{array}$ & 118 & 98.3 & 98 & 81.7 & $<0.01 *$ & $<0.01 *$ \\
\hline \multirow[t]{3}{*}{ Prevention } & 12 & 10 & 119 & 99.2 & 100 & $\begin{array}{c}83 . \\
3\end{array}$ & $<0.01 *$ & $<0.01 *$ \\
\hline & \multicolumn{3}{|c|}{$\begin{array}{l}\text { Pre-test } \\
(n=120)\end{array}$} & \multicolumn{3}{|c|}{$\begin{array}{l}\text { Post-test } \\
(n=106)\end{array}$} & \multirow{2}{*}{\multicolumn{2}{|c|}{ P\# }} \\
\hline & № & & $\%$ & № & \multicolumn{2}{|c|}{$\%$} & & \\
\hline \multirow[t]{2}{*}{ Elderly fallers } & \multicolumn{2}{|l|}{43} & (35.8) & 29 & & & \multicolumn{2}{|r|}{$>0.05$} \\
\hline & \multicolumn{2}{|l|}{ Mean } & S.D. & Mean & \multicolumn{2}{|c|}{ S.D. } & \multicolumn{2}{|r|}{ P\# \# } \\
\hline № of falls & \multicolumn{2}{|l|}{2} & 1.6 & 1.4 & \multicolumn{2}{|c|}{0.7} & \multicolumn{2}{|r|}{$0.05 *$} \\
\hline
\end{tabular}

\#McNemar test,

\#\#Paired T test,

${ }^{*}$ statistical significance at $\mathrm{P}<0.05$

Table 5: Multiple linear regression analysis displaying independent predictors of fall risk assessment score among elderly participa nts

\begin{tabular}{|c|c|c|c|c|c|c|c|}
\hline & \multicolumn{2}{|c|}{$\begin{array}{r}\text { Unstandardized } \\
\text { Coefficients }\end{array}$} & \multirow{2}{*}{$\begin{array}{r}\begin{array}{r}\text { Standardized } \\
\text { Coefficients }\end{array} \\
\text { Beta }\end{array}$} & \multirow[b]{2}{*}{$\mathbf{t}$} & \multirow[b]{2}{*}{$\mathbf{P}$} & \multicolumn{2}{|c|}{$95 \%$ Confidence Interval for B } \\
\hline & B & $\begin{array}{l}\text { Std. } \\
\text { Error }\end{array}$ & & & & Lower Bound & Upper Bound \\
\hline (Constant) & 2.495 & 2.726 & & .915 & .362 & $-2.917-$ & 7.908 \\
\hline Gender & .619 & .373 & .141 & 1.661 & .100 & $-.121-$ & 1.360 \\
\hline Age & .093 & .029 & .264 & 3.171 & $.002 *$ & .035 & .151 \\
\hline Social status & .045 & .160 & .023 & .279 & .781 & $-.274-$ & .363 \\
\hline Education & $-.158-$ & .158 & $-.086-$ & $-1.000-$ & .320 & $-.472-$ & .156 \\
\hline $\begin{array}{l}\text { Vision } \\
\text { Impairment }\end{array}$ & $-.856-$ & .413 & $-.168-$ & $-2.071-$ & $.041 *$ & $-1.677-$ & $-.035-$ \\
\hline $\begin{array}{l}\text { Hear } \\
\text { Impairment }\end{array}$ & .209 & .518 & .035 & .404 & .687 & $-.819-$ & 1.237 \\
\hline $\begin{array}{l}\text { Bladder } \\
\text { Problem }\end{array}$ & $-.844-$ & .819 & $-.089-$ & $-1.031-$ & .305 & $-2.470-$ & .782 \\
\hline Medication no & .170 & .059 & .238 & 2.877 & $.005 *$ & .053 & .287 \\
\hline Previous Falls & $-1.692-$ & .383 & $-.370-$ & $-4.413-$ & $.000 *$ & $-2.454-$ & $-.931-$ \\
\hline Incident Falls & $-.215-$ & .420 & $-.044-$ & $-.512-$ & .610 & $-1.049-$ & .619 \\
\hline $\begin{array}{l}\text { Home Safety } \\
\text { Score }\end{array}$ & $-.227-$ & .084 & $-.219-$ & $-2.705-$ & $.008 *$ & $-.394-$ & $-.060-$ \\
\hline
\end{tabular}




\section{Discussion}

The current study found that the mean score of risk of falling using the CDC falls` risk assessment tool among elderly participants was $4.5 \pm 2.2$

Almost same score was found by Dhargave and Sendhilkumar., $2016^{(16)}(4.3 \pm 2.624)$ who carried out a similar study upon elderly living in long-term care homes in India

The study found out that more than two thirds $(69.2 \%)$ of elderly participants were at risk of falling. Similarly, Gilany et al., $2013^{(12)}$ reported risk of falling among $68 \%$ of participants in a study upon Egyptian elderly living in a rural community

Regarding the individual items of the falls riskassessment checklist, the current study found that 59.2 $\%$ of elderly participants experience fear of falling. This finding is in concordance with Chang etal.,2016 (17) who carried out community based survey in to assess fear of falling among community dwelling older adults in Taiwan and found that $(53.4 \%)$ of study participants experience fear of falling.

As regards previous fall in the last 6 months, it was reported by $35.8 \%$ of elderly participants of the present study, this finding is in agreement with Dhargave and Sendhilkumar., $2016^{(16)}$ and Hnizdo et al., $2013^{(18),}$ who carried out studies in India and USA respectively, and similar percentages of previous fallers (39\%), and $(32 \%)$ of elderly participants respectively. These previous findings are further supported by CDC., 2016 (19) who mentioned that about one third of elderly experience falling.

As regards participants` home safety against falls, 27.5 $\%$ of participants reported risky geriatric home environment. Similarly, Ranweera et al., $2013^{(20)}$ who carried out a study among community elderly in Colombia, reported high house risk level of falling among $26 \%$ of participants

Regarding the effect of the health education intervention program upon ' knowledge of elderly participants, the present study found that there was statistical significant improvement in knowledge score of elderly participants about medications that increased risk of falling in both the posttest and the follow up in comparison with the pretest score $(\mathrm{P}=0.00)$, This finding agrees with a study carried out by Abou ElEnein ., 2012 $2^{(21)}$ who conducted an education program about falls in insurance hospitals in Alexandria, and noticed significant improvement in participants' knowledge after the program.

In addition, Elderly participants` knowledge about environment risk factors of falling improved with statistical significant difference in posttest and follow up in comparison with pretest. This finding is in agreement with an Indian study carried out by Punitha et al., $2015^{(22)}$ who reported statistical significant improvement in the posttest knowledge scores about elderly home safety after conduction of health education intervention about home safety for falls prevention among elderly $(\mathrm{P}<0.001)$.

Furthermore, the present study found that there was statistical significant improvement in knowledge score of elderly participants about falls complications in both the posttest and the follow up in comparison with the pretest score $(\mathrm{P}=0.00)$, this finding is in agreement with Schepens et al., 2011 (23) who carried out an education program in Wayne, USA to promote falls knowledge and preventive behavior upon community older adults and observed statistical significant improvement in the knowledge of the education intervention group posttest $(\mathrm{P}=0.002)$

Moreover, the current study found that there was statistical significant improvement in knowledge score of elderly participants about falls' prevention in both the posttest and the follow up in comparison with the pretest score $(\mathrm{P}=0.00)$, This finding is in accordance with Chen., 2013 ${ }^{(9)}$ who implemented a health education program in a quasi-experimental study in Taiwan to promote falls ' preventive knowledge among community elderly and concluded significant improvement in knowledge of geriatric participants posttest $(\mathrm{P}=0.00)$.

On the other hand, the current study finding is in disagreement with Johnson et al., 2014(24) that concluded non-significant increase in participants knowledge about falls prevention posttest, $(\mathrm{P}=0.9)$, the possible explanation of the nonsignificant improvement is that the study participants were nurses who had high initial awareness about falls risk factors; health care providers (as nurses and doctors) with medical background are expected to have high knowledge regarding falls risk factors, complications and prevention as compared to elderly population.

The current health education intervention showed a significant improvement regarding all knowledge dimension among elderly participants and this success could be attributed to the following reasons: a) health education lectures were carried out in small groups (5 10) to allow for adequate interaction and answering of all elderly's enquiries, if any, b) all knowledge items in the interview questionnaire were covered in the health education educational material, c) all information was explained with comprehensive manner and knowledge items which showed low knowledge score among elderly participants based on pretest results was stressed upon repeatedly and justified in as scientific and simple way.

Number of elderly participants who experienced falling decreased from $(35.8 \%)$ in the pre-test to $(27.4 \%)$ in the 6 months post-test, moreover mean no of falls among faller' participants decreased from (2 \pm 1.6$)$ to $(1.4 \pm 0.7)$ with statistical significant difference $(\mathrm{P}=0.05)$.Similarly Luck et al., 2013 ${ }^{(25)}$ observed significant difference in mean number of falls between intervention group that received education and control group that did not receive the education at follow-up $(2.2 \pm 2.5$ versus $3.7 \pm 4.2)$ in a randomized control trial upon elderly in Germany. 
Multiple linear regression analysis revealed that age, vision impairment, number of medication, previous falling and home safety are significant independent predictors of risk of falling among elderly participants $(\mathrm{P}<0.05)$. This finding is in agreement with (Patil et al., $2017^{(26)}$ who concluded that vision impairment is independent predictor of falling $(\mathrm{P}=0.01)$. That current study finding is also in agreement with (Hammond and Wilson 2013) (27) who considered that medication intake is an independent variable associated with falls in the elderly.

\section{Conclusion:}

The current study concluded that more than two thirds $(69.2 \%)$ of the elderly participants were at risk of falling, $(27.5 \%)$ reported risky geriatric home environment. The implemented health education program was proved to be effective in increasing knowledge and reducing number of falls among geriatric participants risk factors as increased age of elderly participants, presence of visual impairment and increasing number of administered medications, previous falls and risky home environment were proved to be significant independent predictors of risk of falling among elderly participants.

\section{Recommendations}

Further health education sessions are recommended to fill the considerable gap of knowledge as regards falls` risk factors, falls risk assessment, prevention and environmental home safety against falls. They should be conducted in geriatric homes, PHC centers and geriatric clubs to target elderly, their caregivers and geriatric health care professionals, Ongoing research intervention is crucial to guarantee the sustainability of the high knowledge level and preventive practices attained after the health education intervention over longer duration.

\section{References}

1. Sweed HS (2016): Population Ageing - Egypt Report: Middle East Journal of Age and Ageing Volume 13, Issue 2.

2. Hamed AF, Mohammed NA and Aly HY (2017): Elderly Falls Prevalence and associated Factors in Sohag Governorate: The Egyptian Journal of Community Medicine Vol. 35 No. 4

3. Gschwind YJ, Kressig RW and Lacroix A (2013). A best practice fall prevention exercise program to improve balance, strength/power, and psychosocial health in older adults: study protocol for a randomized controlled trial. BMC Geriatr,; 13: 105

4. Centers for Disease Control and Prevention (CDC) (2012). Falls among Older Adults: An Overview http://www.cdc.gov/homeandrecreationalsafety/falls/sdultfalls. $\underline{\mathrm{html}}$

5. Gomes ECC, Marques APO, Leal MCC and Barros BP (2014): Factors associated with the danger of accidental falls among institutionalized elderly individuals: an integrative review. iênc Saúde Coletiva;19(8):3543-51

6. World Health Organization (WHO) (2012). Polices and priority interventions for health aging, p.5
7. Al-Aama $T$ (2011). Falls in the elderly: Spectrum and prevention. Canadian Family Physician, 57, 771-776.

8. Mihaljcic T,. Haines TP, Ponsford J and Stolwyk RJ (2015): Self-awareness of falls risk among elderly patients: characterizing awareness deficits and exploring associated factors, Archives of Physical Medicine and Rehabilitation, vol. 96, no. 12, pp. 2145- 2152

9. Chen SF (2013). Intervention to prevent falls through health education for elderly in Taiwan, Pak. J. Statist. Vol. 29(5), 535-546

10. Gutta S, Joseeph A, Chakraborty A and Alexander AM (2013). Study on the knowledge, attitudes and practices regarding prevention of recurrent falls in the elderly, IOSR Journal of Dental and Medical Sciences (IOSR-JDMS) e-ISSN: 22790853, p-ISSN: 2279-0861. Volume 9, Issue 3 PP 32-38 www.iosriournals.org

11. Liang SS, Silver IF, York $S$ and Phelan EA (2011). Fall Prevention Knowledge, Attitude and Practices of Community Stakeholders and Older Adults, SAGE-Hindawi, Access to Research Journal of Aging Research Volume 2011, Article ID 395357, 9 pages doi:10.4061/2011/395357

12. El-Gilany AA, Hatata $E$, Soliman $S M$ and Refaat $R$ (2013).Prevention of recurrent falls in elderly: a pre-post intervention study in a rural community, Egypt. International Journal of Collaborative Research on Internal Medicine \& Public Health,Vol. 5 No. 4

13. Rubenstein LZ, Vivrette R, Harker JO, Stevens JA, Kramer JB (2011). Validating an evidence-based, self-rated fall risk questionnaire (FRQ) for older adults, J Safety Res; 42(6) 493499.

14. Robertson MC, Gillespie LD (2013): Fall prevention in community-dwelling older adults. JAMA; 309(13): 1406-7

15. Centers for Disease Control and Prevention (CDC) (2015): A Home Fall Prevention Checklist for Older Adults https://www.cdc.gov/steadi/pdf/check_for_safety_brochurea.pdf

16. Wiens CA, Koleba T, Jones CA and Feeny DF (2006). The Falls Risk Awareness Questionnaire: Development and Validation for Use with Older Adults. Journal of Gerontological Nursing, 32(8): 43-50

17. Dhargave $P$ and Sendhilkumar $R$ (2016): Prevalence of risk factors for falls among elderly people living in long-term care homes, Journal of Clinical Gerontology \& Geriatrics 7 99e103 http://creativecommons.org/licenses/ by-nc-nd/4.0/

18. Chang HT, Chen $\mathrm{CH}$ and Chou P (2016): Factors Associated with Fear of Falling among Community-Dwelling Older Adults in the Shih-Pai Study in Taiwan, PLOSONE|DOI:10.1371/journal.pone.0150612

19. Hnizdo S, Archuleta RA, Taylor B, and Kim SC (2013): Validity and reliability of the modified John Hopkins Fall Risk Assessment Tool for elderly patients in home health care, Geriatric Nursing, vol.34, no.5, pp.423-427.

CDC (2016): Centers for Disease Control and Prevention, National Center for Injury Prevention and Control. Web-based Injury Statistics Query and Reporting System (WISQARS).

20. Ranaweera $A D$, Fonseka $P$, Arachchi $P$ and Siribaddana $S H$ (2013): Incidence and risk factors of falls among the elderly in the district of Colombo, the Ceylon Medical Journal; 58: 100 106

21. Abou El Enein NY, Abd El Ghany AS and Zaghloul AA (2012): Knowledge and performance among nurses before and after a training programme on patient falls, Journal of Nursing 2, 358364.

22. Punitha JS, Vidhya T and Sreelekha B (2015): Effectiveness of preparatory informatics regarding home safety for elderly on knowledge among caregivers at a selected rual community in Bengaluru, India: International Journal of Nursing and Patient Safety \& Care (TJPRC: IJNPSC) Vol. 1, Issue 2, Dec 2015, 61-64

23. Schepens SL, Panzer V, \& Goldberg A (2011): Research Scholars Initiative-Randomized controlled trial comparing tailoring methods of multimedia-based fall prevention 
Ismail GM. EJGG.2018; 5(2): 1-7

education for community-dwelling older adults. American Journal of Occupational Therapy, 65, 702-709. doi: 10.5014/ajot.2011.001180

24. Johnson M, Hime N, Zheng C, Tran DT, Kelly L and Siric K (2014): Differences in nurses' knowledge, behavior and patient falls incidents and severity following a falls e-learning program: Journal of Nursing Education and Practice, Vol. 4, No. 4 www.sciedu.ca/jnep

25. Luck T, Motzek T, Luppa M, Matschinger $\mathrm{H}$, Fleischer $\mathrm{S}$, Sesselmann $Y$, Roling $G$, Beutner K, Koing H, Berhens $\mathrm{J}$ and Riedel-Heller SG (2013): Effectiveness of preventive home visits in reducing the risk of falls in old age: a randomized controlled trial, Clinical Interventions in Aging :8 697-702
26. Patil SS, Suryanarayana SP, Dinesh R, Shivraj NS, Murthy NS (2017): Risk factors for falls among elderly: A communitybased study, International Journal of Health \& Allied Sciences, IP: 41.69.246.77 from http://www.ijhas.in

27. Hammond T and Wilson A (2013): Polypharmacy and Falls in the Elderly: A Literature Review. Nurs Midwifery Stud; 2(2):171-5 